BMJ Open

Sport \&

Exercise

Medicine

\title{
Mindfulness-based intervention for tennis players: a quasi-experimental pilot study
}

\author{
Sabine Hoja, ${ }^{\oplus 1}$ Petra Jansen ${ }^{\top 2}$
}

To cite: Hoja S, Jansen P. Mindfulness-based intervention for tennis players: a quasiexperimental pilot study. BMJ Open Sport \& Exercise Medicine 2019;5:e000584. doi:10.1136/ bmjsem-2019-000584

Accepted 5 August 2019

\section{Check for updates}

\section{(C) Author(s) (or their} employer(s)) 2019. Re-use permitted under CC BY-NC. No commercial re-use. See rights and permissions. Published by BMJ

${ }^{1}$ Faculty of Psychology, Pedagogy and Sports Science, University of Regensburg, Regensburg, Germany ${ }^{2}$ University of Regensburg, Regensburg, Germany

Correspondence to Dr Sabine Hoja; sabine.hoja@ur.de

\section{ABSTRACT}

Objectives Mindfulness-based interventions in the context of sports have been shown to result in higher mindfulness scores and improved physiological and psychological parameters. The goal of this pilot study was to investigate the effects of a newly developed sevensession mindfulness-based intervention, mindful ${ }^{\mathrm{e}}$ motions, on German tennis players.

Methods The study was conducted in a pre-post test design with an intervention and a control group. Before and after the mindfulness-based stress reduction training the following dependent measurements were assessed: athletic performance (serve accuracy) and psychological performance indicators (mindfulness, stress and competition anxiety).

Results The results indicate a better performance of the intervention group for the difference scores between posttest and pre-test in one of the sport-related anxiety factors, the concentration disturbances index.

Conclusion In order to further investigate the effects of this mindfulness-based intervention in competitive sports, additional studies with a larger number of participants have to follow.

\section{INTRODUCTION}

The term mindfulness describes the awareness of present moment experience in a non-judgmental way. ${ }^{1}$ According to Tang et al., ${ }^{2}$ mindfulness comprises the aspects of attention control, emotion regulation and self-awareness. The research on mindfulness has been grown exponentially since the year 2000 and the need for more research was claimed from leading researchers in this field. ${ }^{3}$ In the field of sports science research, mindfulness-based approaches seem to be promising, especially under 'choking under pressure' situations, where athletes fail to meet self-imposed performance expectations in critical situations. ${ }^{4}$

Until now, two sports-related mindfulness programmes exist. The Mindfulness-Acceptance-Commitment approach combines mindfulness exercises and acceptance techniques within a 7-week course ${ }^{5}$ and is based on the acceptance commitment

\section{What are the new findings}

- Mindfulness interventions are feasible in amateur tennis players.

- The programme mindful ${ }^{\mathrm{e}}$ motions helps to decrease sport-related concentration problems.

- Mindfulness might be a promising tool to stabilise athletes during their whole careers.

theory with its main goal to strengthen the people for the handling of changing life situations. ${ }^{6}$ Mindful Sports Performance Enhancement is a 4-week mindfulness programme ${ }^{7}$ based on Kabat-Zinn's mindfulness-based stress reduction $(\mathrm{MBSR})^{8}$ and the mindfulness-based cognitive therapy. ${ }^{9}$ In a sporting context, mindfulness-based interventions have been shown to improve mindfulness as well as physiological (eg, resting heart rate and salivary cortisol level) and psychological performance surrogates (eg, flow and anxiety). ${ }^{10}$ The results of a systematic review, including studies of all kinds of study designs, showed large effect sizes for the improvement of mindfulness, flow and performance but lower effect sizes for competitive anxiety. In those studies, the control groups did not receive any treatment. However, according to the authors, it is difficult to make a strong causal claim about the benefits these strategies offer. $^{11}$ Little has been investigated concerning the effects of mindfulness on the measurable athletic performance in the context of competitive sports. ${ }^{12}$

The goal of this pilot study was to investigate whether a newly developed mindfulness-based intervention, the so-called mindful ${ }^{e}$ motions programme, ${ }^{13}$ can improve actual motor performance and decrease sports anxiety when tennis players who play tennis regularly and participate in competitions experience a situation under pressure. The duration of this programme equals the same amount of time as the classical MBSR. The influence of mindfulness for a sport situation under pressure for non-professionals has not been investigated 
Table 1 Demographic data of the experimental group and the control group

\begin{tabular}{llll}
\hline & $\begin{array}{l}\text { Experimental } \\
\text { group }(\mathbf{n}=8)\end{array}$ & $\begin{array}{l}\text { Control group } \\
(\mathbf{n = 8})\end{array}$ & P values \\
\hline Mean age (years) (SD) & $26.38(7.56)$ & $26.63(5.95)$ & 0.942 \\
\hline Sex & 7 females & 7 males & $0.003^{*}$ \\
$\begin{array}{l}\text { Tennis experience } \\
\text { (years) }(S D)\end{array}$ & $19.50(7.19)$ & $19.38(5.32)$ & 0.969 \\
$\begin{array}{l}\text { Tennis practice } \\
\text { (hours per week) }(S D)\end{array}$ & $3(0.756)$ & $2(0.926)$ & 0.033 \\
\hline
\end{tabular}

${ }^{\star}$ Significant $<0.01$.

until now. Furthermore, we wanted to examine the feasibility of this newly developed mindfulness training for the sports context.

\section{METHODS Participants}

The study was conducted with German tennis players $(\mathrm{n}=16)$ with a mean age $\mathrm{M}=26.50$ years ( $\mathrm{SD}=6.57$ years), all from the same tennis club (demographic data are given in table 1). Players were recruited with the assistance of a tennis trainer; none of them had experience in the field of meditation or mindfulness. All subjects gave written informed consent in accordance with the Declaration of Helsinki. ${ }^{14}$

\section{Measurements}

Measurement of athletic performance

Serve accuracy was chosen as the measurable performance index. The tennis players had to aim 16 serves into designated target areas. They were allowed to perform a second attempt of every serve if the first one was invalid or off-target. A total score of hits was calculated with a maximum of 16 hits. In order to expose the participants to a more stressful situation, the other tennis players sat in the tennis hall and watched the serves. They were not allowed to give feedback to the serving player but observed him or her and were allowed to talk to each other quietly to simulate the atmosphere of an audience.

\section{Mindful Attention Awareness Scale}

The Mindful Attention Awareness Scale (MAAS) consists of 15 items, which investigate the dispositional mindfulness as a one-dimensional structure.$^{15}$ Items are rated on a 6-point Likert scale from 1 (almost always) to 6 (almost never). In the German version of the MAAS, Cronbach's alpha $\alpha=0.83 .{ }^{16}$ The MAAS is useful for participants without meditation experience.

\section{Perceived Stress Questionnaire}

The Perceived Stress Questionnaire (PSQ) assesses subjectively experienced stress, independent of a specific occasion ${ }^{17}$ with 20 items being rated on a 4-point Likert scale from 1 (almost never) to 4 (usually). The German version reveals values for Cronbach's alpha $\alpha>0.70 .^{18}$
Example items are: 'I am feeling calm', 'I am frustrated' and 'I have many worries'.

Competition anxiety inventory-trait

This German questionnaire dealing with sport-specific anxiety consists of 12 items that are rated on a 4-point Likert scale from 1 (not at all) to 4 (very). Items are grouped into three subcategories (somatic anxiety, concern and concentration disturbances). All three subscales show values for Cronbach's alpha $\alpha>0.70 .{ }^{19}$ One of the questions might be, for example: 'Prior to competitions, I am nervous'.

\section{Procedure}

Tennis players were divided into an experimental group, who received a mindfulness-based intervention for 7 weeks in addition to their normal tennis training, and a control group without any additional training. Since randomisation was not practicable, the tennis players were allocated according to their training group into either the experimental or control group, which means that the members of a training group were not separated during this study. The group sessions of the mindfulness-based stress reduction training were conducted by a professional MBSR teacher and lasted 120 min each. Furthermore, a daily practice of $30 \mathrm{~min}$ was recommended. Participants of the experimental group had to attend at least six of the seven sessions. The testing (serve accuracy and psychological questionnaires) for both groups was applied before (pre-test) and after the 7-week intervention (post-test).

\section{Mindfulness-based intervention}

The programme, mindful ${ }^{e}$ motions, contains seven sessions of (a) basic information (theoretical rationale for mindfulness), (b) perception and attention, (c) body and stress (conscious awareness of the body limits), (d) emotions and thoughts, (e) values, (f) acceptance and (g) commitment and self-care. It contains elements of meditation, body scan and mindfulness yoga as well as value education. ${ }^{13}$

\section{Statistical analysis}

Difference scores between post-test and pre-test were calculated for each of the six dependent variables (hits, MAAS, PSQ Competition anxiety inventory-trait (WAI-T) somatic anxiety, WAI-T concern and WAI-T concentration disturbances). Due to the small number of participants, a non-parametric analysis was conducted for each of the difference scores between the post-test and the pre-test using the one-tailed Mann-Whitney U test. 'Group' served as a between-subject factor.

\section{RESULTS}

All descriptive data of the pre-test and post-test are given in table 2.

Regarding the six Mann-Whitney U tests, there was a group effect only for the WAI-T concentration disturbances score, $\mathrm{U}=14, \mathrm{z}=-1.939$ and $\mathrm{p}=0.032$ (one-tailed). Figure 1 shows that the groups did not differ in the 
Table 2 Descriptive values (means, SD) of the pre-test and post-test for the experimental group and the control group in the different dependent measurements

\begin{tabular}{llllllll}
\hline & & $\begin{array}{l}\text { Athletic } \\
\text { performance }\end{array}$ & MAAS & PSQ & WAI-T anxiety & WAI-T concern & $\begin{array}{l}\text { WAI-T } \\
\text { concentration }\end{array}$ \\
\hline \multirow{2}{*}{ EG } & Pre-test & $8.37(3.06)$ & $58.50(7.40)$ & $47.50(23.65)$ & $9.37(3.33)$ & $8.62(2.50)$ & $9.12(1.89)$ \\
& Post-test & $8.87(2.64)$ & $53.62(8.38)$ & $43.54(16.38)$ & $9.50(3.34)$ & $9.00(2.39)$ & $8.50(1.19)$ \\
CG & Pre-test & $7.50(2.39)$ & $64.75(9.09)$ & $46.25(16.82)$ & $9.62(2.39)$ & $10.50(2.45)$ & $9.13(2.64)$ \\
& Post-test & $7.37(3.42)$ & $56.00(8.71)$ & $44.95(16.35)$ & $9.37(1.99)$ & $11.00(2.92)$ & $10.13(3.31)$ \\
\hline
\end{tabular}

CG, control group; EG, experimental group; MAAS, Mindful Attention Awareness Scale; PSQ, Perceived Stress Questionnaire; WAI-T, competition anxiety inventory-trait.

pre-test but in the post-test where the control group received higher values than the experimental group. For the other five measurements, there was no significant group effect in the difference score between pre-test and post-test (Mann-Whitney $\mathrm{U}$ tests, all $\mathrm{p}>0.15$, one-tailed).

\section{DISCUSSION}

Our results show that the mindfulness-based intervention, mindful ${ }^{e}$ motions, may have contributed to decreased sport-related anxiety in terms of concentration problems. Furthermore, we demonstrated that such a mindfulness programme with long-lasting sessions of 120 min each is feasible in amateur tennis players. The missing significant improvement regarding the number of hits (tennis serves) of the experimental group in comparison with the control group could be explained by the fact that the pressure was not sufficiently high and for that did not affect the performance. Gröpel and Mesagno $^{20}$ showed that the most effective interventions were pre-performance routines, quiet eye training, lefthand contractions and acclimatisation training. Since the phenomenon 'choking under pressure' can either be explained with a distraction or the self-focus model, it seems reasonable that mindfulness interventions do

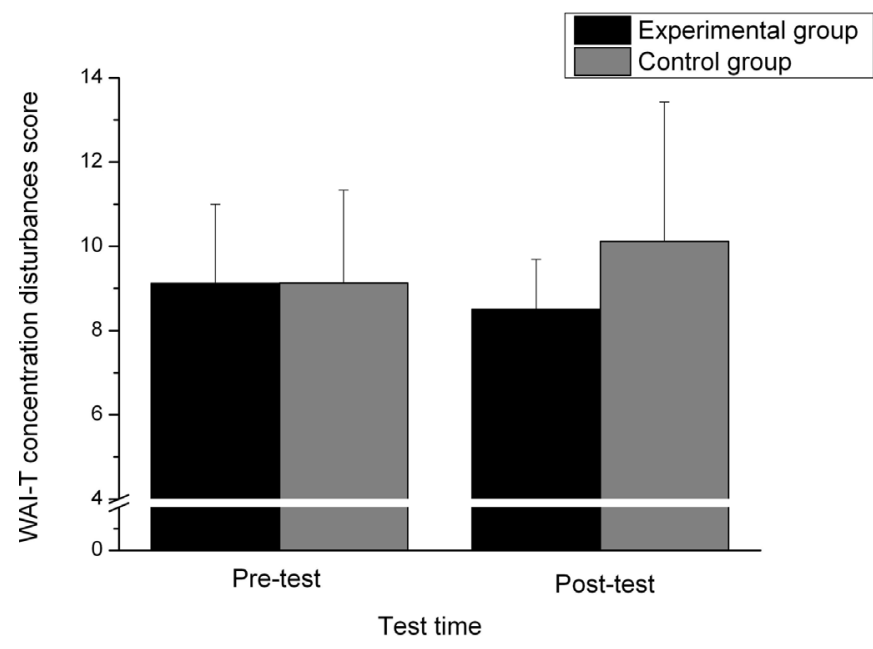

Figure 1 Means and SDs of WAI-T concentration disturbances scores for pre-test and post-test for the experimental group and the control group. WAI-T, competition anxiety inventory - trait. have an effect especially for the dimension concentration in sports performance.

\section{Mindfulness and the perception of stress in sports}

Changes in mindfulness and the perception of stress were not statistically significant. One reason for this might be that the mindfulness questionnaire applied here measured more the component of trait mindfulness compared with the awareness of mindfulness in a specific situation. Other reasons might be the small number of participants and the fact that the assignment to the two groups had not been randomised. Another limitation is the different distribution of female and male tennis players in the experimental and control groups, respectively. These limiting factors could be overcome in further studies with larger cohorts and a randomised distribution to obtain more relevant results.

\section{CONCLUSION}

This pilot study has shown that the application of a mindfulness-based intervention in tennis players who are ambitious but not professional is feasible in amateur athletes-mindfulness interventions should not be limited to professional athletes. Within the limitations of the quasi-experimental design, this study suggests that mindfulness intervention in sports has the most important effect on concentration problems, which is highly relevant in sports competition.

Acknowledgements We are grateful for the mindfulness-based intervention, mindful ${ }^{\mathrm{e}}$ motions, applied by Dr. Florian Seidl, MBSR teacher.

Contributors SH helped to design the study, organised the data acquisition and wrote the first draft of the paper. PJ designed the study and discussed the first draft of the paper.

Funding The authors have not declared a specific grant for this research from any funding agency in the public, commercial or not-for-profit sectors.

Competing interests None declared.

Patient consent for publication Participans gave written informed consent.

Ethics approval The study has been approved by the Ethics Committee of the University of Regensburg (reference number: 17-810-101).

Provenance and peer review Not commissioned; externally peer reviewed.

Open access This is an open access article distributed in accordance with the Creative Commons Attribution Non Commercial (CC BY-NC 4.0) license, which permits others to distribute, remix, adapt, build upon this work non-commercially, and license their derivative works on different terms, provided the original work is 
properly cited, appropriate credit is given, any changes made indicated, and the use is non-commercial. See: http://creativecommons.org/licenses/by-nc/4.0/.

\section{REFERENCES}

1. Kabat-Zinn J. Wherever you go, there you are: mindfulness meditation in everyday life. New York (NY): Hyperion, 1994.

2. Tang Y-Y, Hölzel BK, Posner MI. The neuroscience of mindfulness meditation. Nat Rev Neurosci 2015;16:213-25.

3. Van Dam NT, van Vugt MK, Vago DR, et al. Mind the hype: a critical evaluation and prescriptive agenda for research on mindfulness and meditation. Perspect Psychol Sci 2018;13:36-61.

4. Mesagno C, Beckmann J. Choking under pressure: theoretical models and interventions. Curr Opin Psychol 2017;16:170-5.

5. Gardner FL, Moore ZE. The psychology of enhancing human performance: the Mindfulness-Acceptance-Commitment (MAC) approach. New York (NY): Springer, 2007.

6. Hayes SC, Strosahl KD, Wilson KG. Acceptance and commitment therapy: the process and practice of mindful change. 2nd edition. New York (NY): The Guilford Press, 2012.

7. Kaufman KA, Glass CR, Arnkoff DB. Evaluation of mindful sport performance enhancement (MSPE): a new approach to promote flow in athletes. J Clin Sport Psychol 2009;3:334-56.

8. Kabat-Zinn J. An outpatient program in behavioral medicine for chronic pain patients based on the practice of mindfulness meditation: theoretical considerations and preliminary results. Gen Hosp Psychiatry 1982;4:33-47.

9. Segal ZV, Williams JMG, Teasdale JD. Mindfulness-based cognitive therapy for depression: a new approach to preventing relapse, 2002.

10. Bühlmayer L, Birrer D, Röthlin P, et al. Effects of mindfulness practice on Performance-Relevant parameters and performance outcomes in sports: a Meta-Analytical review. Sports Med 2017;47:2309-21.
11. Noetel M, Ciarrochi J, van Zanden B, et al. Mindfulness and acceptance approaches to sporting performance enhancement: a systematic review. Int Rev Sport Exerc Psychol 2017;2:1-37.

12. Hoja S, Zirkelbach J, Jansen P. Achtsamkeit - auch ein Megatrend im Leistungssport? [Mindfulness - also a megatrend in competitive sports?]. Sports Orthopaedics and Traumatology 2018;34:38-44.

13. Jansen P, Seidl F, Richter S. Achtsamkeit im Sport [Mindfulness in sports]. Berlin: Springer, 2018.

14. World Medical Association. World Medical association Declaration of Helsinki: ethical principles for medical research involving human subjects. JAMA 2013;310:2191-4.

15. Brown KW, Ryan RM. The benefits of being present: mindfulness and its role in psychological well-being. J Pers Soc Psychol 2003;84:822-48.

16. Michalak J, Heidenreich T, Ströhle G, et al. Die deutsche Version der Mindful Attention and Awareness Scale (MAAS) Psychometrische Befunde zu einem Achtsamkeitsfragebogen [German version of the Mindful Attention an Awareness Scale (MAAS) - psychometric features of a mindfulness questionnaire]. Zeitschrift für Klinische Psychologie und Psychotherapie 2008;37:200-8.

17. Levenstein S, Prantera C, Varvo V, et al. Development of the perceived stress questionnaire: a new tool for psychosomatic research. J Psychosom Res 1993;37:19-32.

18. Fliege $H$, Rose $M$, Arck $P$, et al. Validierung des "Perceived Stress Questionnaire“ (PSQ) an einer deutschen Stichprobe [Validation of the "Perceived Stress Questionnaire" (PSQ) in a German cohort]. Diagnostica 2001;47:142-52.

19. Brand R, Graf K, Ehrlenspiel F. Das Wettkampfangst-Inventar-Trait [Competition anxiety inventory-trait]. Das Wettkampfangst-Inventar 2009:15-69.

20. Gröpel P, Mesagno C. Choking interventions in sports: a systematic review. Int Rev Sport Exerc Psychol 2017;32:1-26. 